\title{
Observations on Four Cases of Brooke-Spiegler Syndrome
}

\author{
Mihaela Leventer ${ }^{1}$, Casandra Coltoiu ${ }^{1, *} * \mathbb{D}$, Alexandra Zota ${ }^{1}$, Tiberiu Tebeica ${ }^{1}$, \\ Carmen Lisievici ${ }^{1}$ and Alina Martinescu ${ }^{2}$ \\ 1 “Dr. Leventer Centre”, Monetariei Street, no 8, 011216 Bucharest, Romania; \\ mihaela.leventer@yahoo.com (M.L.); alexandra_zota@yahoo.com (A.Z.); tebeica@gmail.com (T.T.); \\ lisievici.carmen@yahoo.com (C.L.) \\ 2 “Ovidius University", Mamaia Boulevard, no 124, 900527 Constanta, Romania; \\ alinamartinescu@yahoo.co.uk \\ * Correspondence: casandra.coltoiu@yahoo.com; Tel.: +40-744666120
}

Received: 23 August 2020; Accepted: 29 September 2020; Published: 30 September 2020

\begin{abstract}
Background: Brooke-Spiegler Syndrome is a rare genetic autosomal dominant disorder with variable penetrance. Its main feature consists of the development of multiple adnexal tumors that originate from the follicular-sebaceous-apocrine unit, most commonly: cylindromas, trichoepitheliomas and spiradenomas. Case presentation: We present four cases of Brooke-Spiegler Syndrome found in our clinic, as well as their clinicopathological traits and the surgical techniques used in their management. The familial history of three of the presented cases supports the genetic component of the disease. Cylindromas, spiradenomas and trichoepitheliomas coexisted in one of the cases presented. The therapeutic options used were electrocautery, $\mathrm{CO} 2$ laser, as well as tumor debulking followed by closure with metal staples. Discussion: The treatment remains a challenge and must be individualized based on the type, location and number of the lesions. Conservative methods such as $\mathrm{CO} 2$ laser and tumor debulking accompanied by closure with metal staples remain a viable option taking into account the large number of lesions. As patients usually develop multiple neoplasms throughout their lifetime, repeated procedures may be needed. Conclusion: Considering the few numbers of Brooke-Spiegler syndrome cases in the current literature, the authors report these patients in order to increase awareness and to help establish the most appropriate approach in managing the disease.
\end{abstract}

Keywords: genodermatosis; adnexal lesions; individualized treatment

\section{Introduction}

Brooke-Spiegler syndrome is a rare entity characterized by the association of multiple trichoepitheliomas, cylindromas, and spiradenomas. Multiple familial tricoepithelioma-1 (MFT-1) constitutes a phenotypic variant of the disease which is manifested by the development of numerous trichoepitheliomas in the absence of accompanying cylindromas, spiradenomas or cylindrospiradenomas [1-3]. The form of Brooke-Spiegler syndrome that is characterized only by the presence of cylindromas, also known as familial cylindromatosis, represents another rare phenotypic variant [4]. Moreover, there were also patients reported in the literature presenting with only spiradenomas or spiradenocylindromas [5]. In 5-10\% of cases, the malignant transformation of preexisting lesions occurs. Therefore, lifetime clinical monitoring is recommended [6].

The gene involved in the etiopathogenesis of the disease is the CYLD gene (cylindromatosis gene), a tumor suppressor located on chromosome 16q12-q13 [1]. People with Brooke-Spiegler syndrome are born with a mutation in one of the two copies of the CYLD gene in each cell. This mutation prevents the cell from making functional CYLD protein from the altered copy of the gene. However, enough protein is usually produced from the other normal copy of the gene in order to regulate 
cell growth effectively [7]. There appear to be no genotype-phenotype correlations with respect to the severity of the disease, the possibility of malignant transformation and the development of extracutaneous lesions. Variability of phenotypic expression between and within families with the same germline CYLD mutation has been documented [7-9]. We will describe the cases of four patients diagnosed with Brooke-Spiegler Syndrome in our clinic.

\section{Case Presentation Section}

Case 1: A 32-year-old female presented in our clinic with multiple millimetric skin-colored papules on the posterior thorax and the face. The first lesion appeared 5 years ago, the evolution being marked subsequently by the rise in number and diameter of the lesions. There was no relevant personal or familial history. The cutaneous examination revealed numerous translucent, asymptomatic papules, of 1-5 mm in diameter, some of them coalescing, localized on the posterior thorax and face, predominantly on the nasolabial folds where they were symmetrically distributed (Figure 1). A biopsy of a facial lesion was taken which showed histopathologic findings consistent with the diagnosis of trichoepithelioma (Figure 2). The cutaneous tumors were treated by electrosurgery.

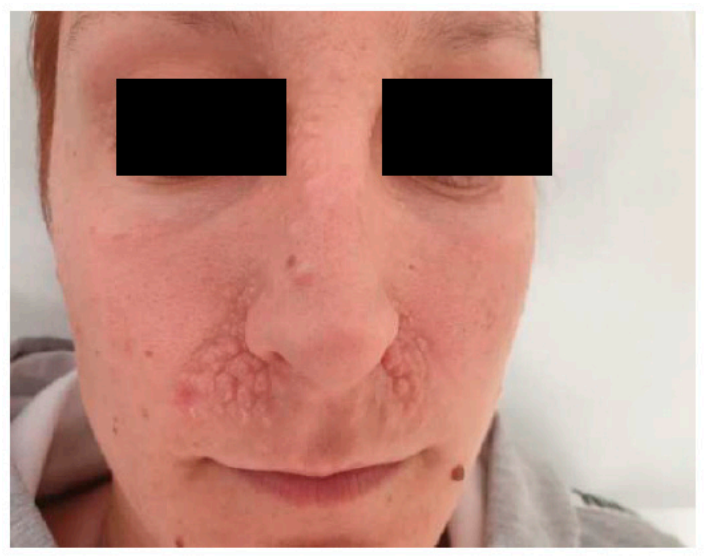

(A)

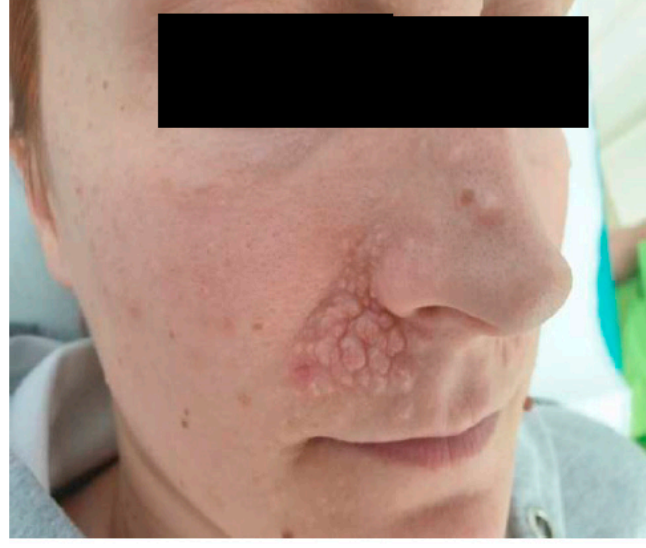

(B)

Figure 1. (A,B) Multiple facial trichoepitheliomas localized predominantly on the nasolabial folds, with a symmetrical distribution.

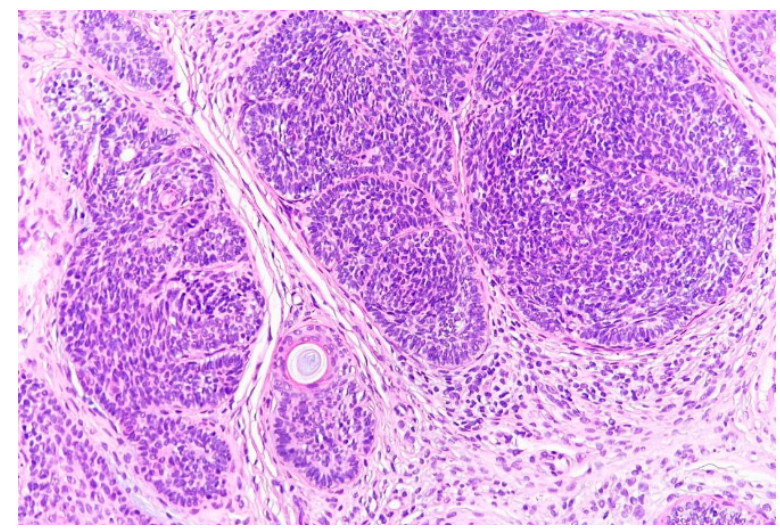

Figure 2. Trichoepithelioma (basaloid cells organized in a lobular pattern similar to that of the basal cell carcinoma, with cribriform aspect due to the horn cysts).

Case 2: An 18-year-old male patient arrived at our clinic with few brown-yellowish, asymptomatic nodules on the scalp and on the lateral aspects of the fifth fingers, bilaterally. The patient reported that his mother, his mother's sister and a cousin presented similar lesions, whereas his grandfather was known to have cylindromas. On examination, five firm, brown-yellowish, asymptomatic nodules 
were seen on the occipital region of the scalp and the lateral aspect of the fifth digits of the hand, bilaterally (Figures 3 and 4) The histopathologic exam established the diagnosis of trichoepitheliomas. The treatment consisted of electrosurgery of the lesions, with favorable evolution.

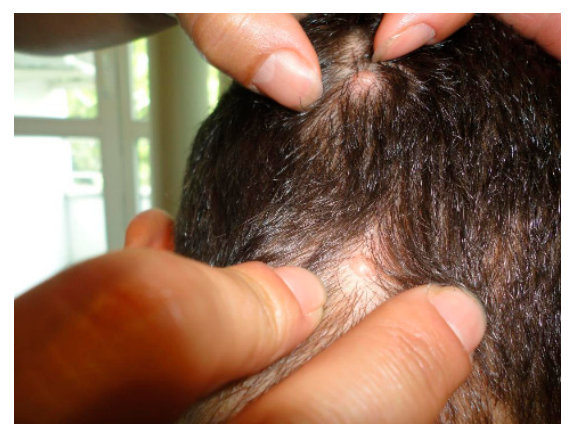

Figure 3. Scalp trichoepitheliomas.

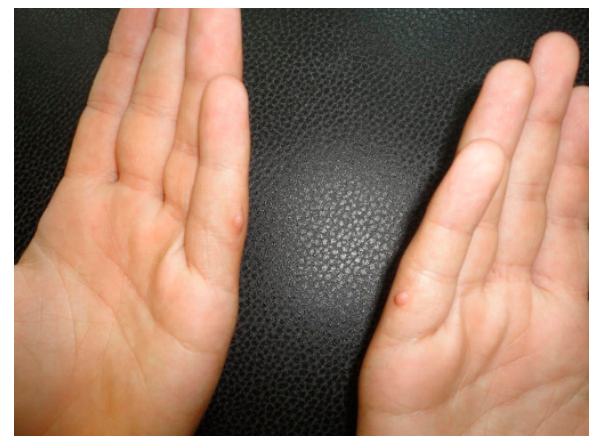

Figure 4. Bilateral trichoepitheliomas on the lateral aspect of the 5 th digits.

Case 3: A 45-year-old female patient, the mother of the previous patient (Figure 5), presented with a brown-yellowish nodule located on the scalp as well as a few skin-colored, millimetrical papules on the nasolabial folds with onset at the age of 13 years. The physical examination revealed a firm, brown-yellowish, well-demarcated, asymptomatic nodule on the scalp (Figure 6), as well as few skin-colored, asymptomatic papules, $3-5 \mathrm{~mm}$ in diameter located on the nasolabial folds. The biopsies taken confirmed the diagnosis of cylindroma on the scalp and trichoepithelioma on the face. The cylindroma was removed by surgical excision, whereas the facial trichoepitheliomas were treated by electrosurgery.

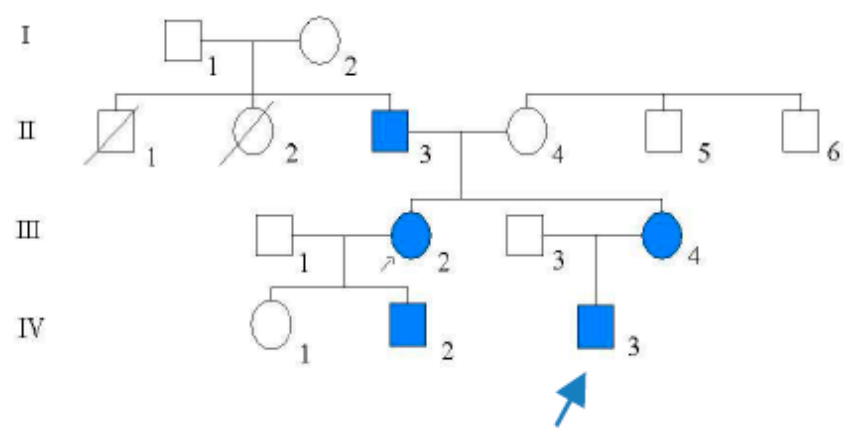

Figure 5. Genealogical tree for Case nos. 2 and 3. 


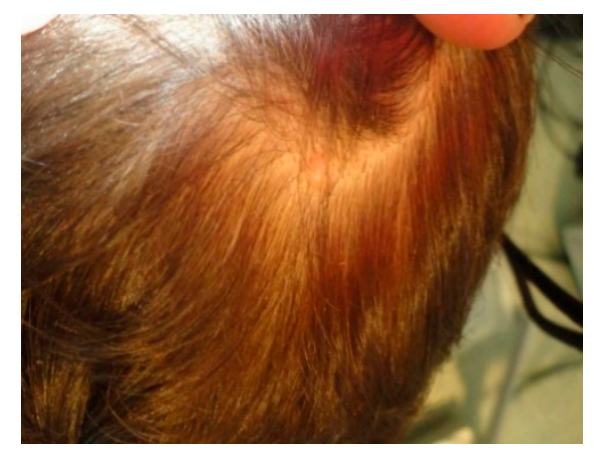

Figure 6. Scalp cylindroma.

Case 4: A 62-year-old female patient presented with erythematous nodules on the scalp and trunk as well as skin-colored papules on the face. The patient stated that her father and sister showed similar, unique scalp nodules. The clinical examination revealed the presence of numerous firm, erythematous, asymptomatic nodules, some of them confluent, with smooth surface, accompanied by telangiectasias (Figures 7 and 8) Simultaneously, multiple skin-colored papules, 1-8 $\mathrm{mm}$ in diameter, were identified on the face (Figure 9) The patient's general health was normal and routine laboratory investigations were within normal limits. Biopsies from two nodules of the scalp were taken. They showed typical features of cylindroma (Figure 10) and spiradenoma, respectively. Regarding the facial papules, the histology revealed trichoepitheliomas. Furthermore, a tumoral lesion of the anterior thorax was excised. The histopathological exam confirmed the diagnosis of superficial basal cell carcinoma.

Some of the cutaneous tumors on the scalp allowed removal with a medial incision followed by curettage, tumor debulking, electrocautery and closure with metal staples. The facial lesions were treated with a $\mathrm{CO}_{2}$ laser that facilitates the tissue vaporization in a controlled fashion and simultaneously produces hemostasis (Figure 11). The patient returned for rigorous follow-up and gradual removal of the cutaneous tumors in multiple stages.

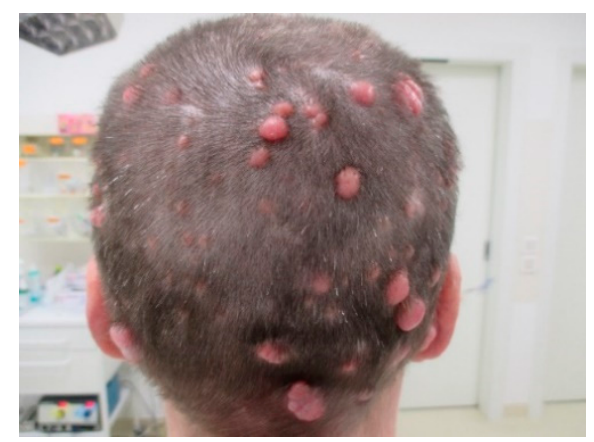

Figure 7. Scalp cylindromas and spiradenomas.

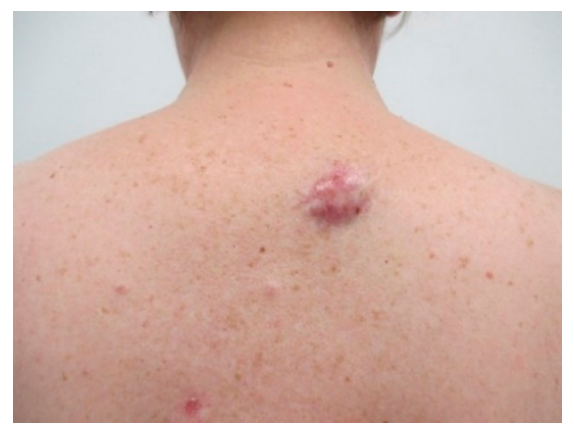

Figure 8. Cylindroma of the posterior thorax. 


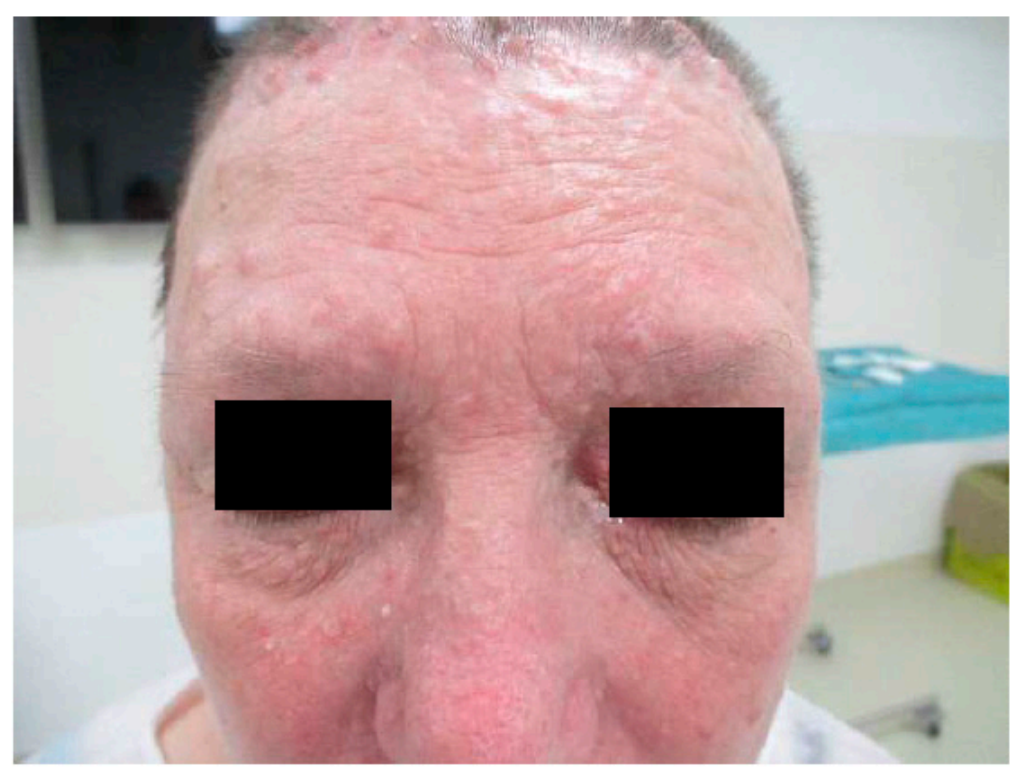

Figure 9. Multiple facial trichoepitheliomas.

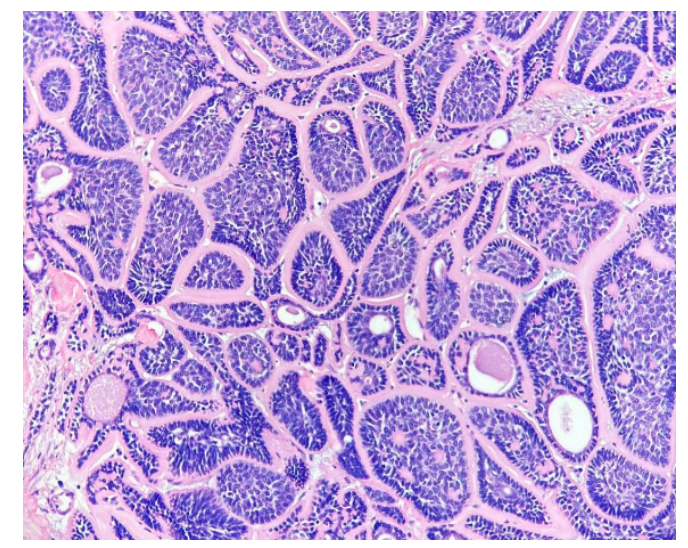

Figure 10. Cylindroma (tumoral islands made of two distinct cellular populations arranged in a "puzzle".

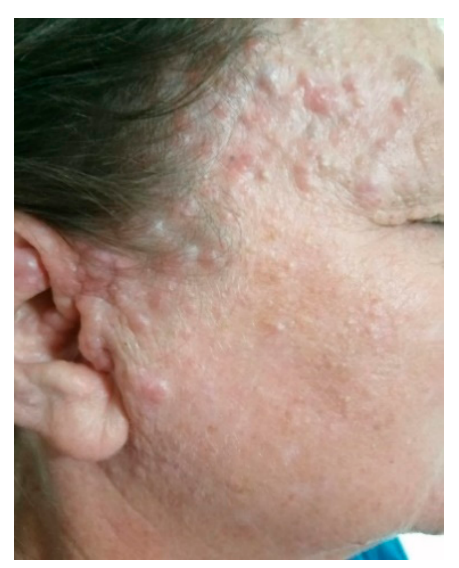

(A)

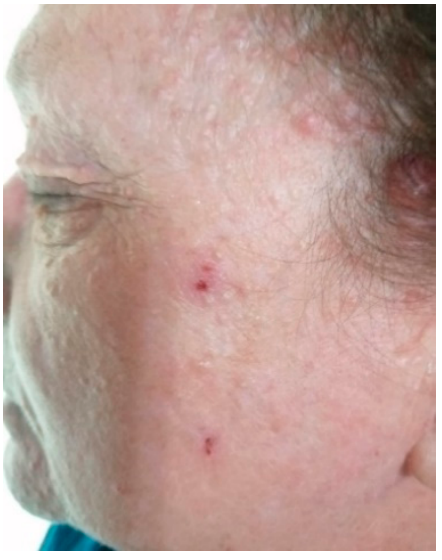

(B)

Figure 11. (A,B): Untreated vs. treated area with $\mathrm{CO}_{2}$ laser. 
Due to the constant recurrence of the lesions, the patient is still followed-up in our clinic, where she periodically benefits from $\mathrm{CO}_{2}$ laser therapy. This enables a reduction in the dimension of the lesions with a satisfactory cosmetic result.

In all the four cases presented, a diagnosis of Brooke-Spiegler syndrome was suggested based on the clinical findings together with the histopathological exam. Informed consent was obtained from the patient.

\section{Discussion}

Brooke-Spiegler Syndrome represents an autosomal dominant genodermatosis with variable penetrance which increases with age (60-100\%). It is the result of mutations in the CYLD gene located on the chromosome 16q12-q13. These mutations are encountered in $80-85 \%$ of cases [10]. The absence of a family medical history of cutaneous tumors regarding the first case presented may be the result of a de novo mutation or an incomplete penetrance as well as the variable expression of the CYLD gene [11,12].

In the familial forms, a phenotypic variability is found (different lesions, different severity), which confirms the absence of correlation between genotype and phenotype. Three of our patients had other relatives with similar cutaneous lesions, supporting the genetic component of the disease.

The involved gene has 20 exons of which the first three are untranslated and extends over approximately $56 \mathrm{~kb}$ of genomic DNA. In regulating the action of nuclear factor-kappa-B, the CYLD protein allows cells to respond properly to signals to self-destruct when appropriate, such as when the cells become abnormal. Mutations in the CYLD gene lead to resistance to apoptosis and facilitate tumor development [13].

As we found in our cases, the most encountered cutaneous lesions are trichoepitheliomas, cylindromas, and spiradenomas. These adnexal tumors present a controversial histogenesis, share the same anatomical distribution and can occur concomitantly, close together, in the same patient. An eloquent example in this direction was that of the fourth case we presented, where the same patient presented all the three lesions.

Regarding trichoepithelioma, it is known to present a follicular differentiation. The origin of cylindroma and spiradenoma is controversial, constituting an apocrine, as well as an eccrine source [14]. Nevertheless, more recent studies claim that both cylindroma and spiradenoma are in fact low differentiated follicular tumors. This theory is supported by the expression of CD 200 in both types of lesions whereas the eccrine tumors are CD 200 negative [15].

The cutaneous lesions typically increase in number and size throughout their lifetime and become frequently disfiguring, with significant psychological, professional, and social repercussions.

Cylindromas are benign tumors that increase slowly and that are often confined to the cephalic extremity. They present as red, pink or bluish papules or nodules ranging from a few millimeters to several centimeters in size. When the cylindromas are located in the scalp and coalesce, they form a confluent mass, historically termed "turban tumors" [16]. Rarely, they are accompanied by pain or paresthesia in case of nerve compression due to tumor growth. Rapid enlargement, bleeding or ulceration suggest a malignant transformation, reported in $5-10 \%$ of cases [17].

On histopathology, cylindromas are well circumscribed, but unencapsulated tumors, composed of two distinct cell types arranged in lobules with a "jigsaw puzzle" pattern. Typically, cylindromas feature hyaline globules in the center of the islands, which may also associate a conspicuous (Periodic Acid Schiff) PAS-positive basement membrane. In each tumor aggregate, large cells with abundant cytoplasm and vesicular nucleolus are confined to the center, whereas the periphery consists of basaloid, small, monomorphic, hyperchromatic cells. The malignant variant may lose the jigsaw appearance and shows a more infiltrative growing pattern, with cytologic atypia, namely, atypical mitoses and conspicuous nucleoli $[18,19]$.

Spiradenomas present as single or multiple variably sized purplish nodules located on the head, neck, trunk or extremities [20]. 
Unlike cylindromas, histologically, spiradenomas are encapsulated tumors, characterized by the presence of one or more well-demarcated basophilic nodules in the dermis. Similar to cylindromas, they contain two types of cells: some small, basaloid cells with hyperchromatic nuclei, located in the periphery of the lobules, and some which are larger, pale with ovoid nuclei and conspicuous nucleolus-present in the center of the islands. The tumor may contain duct-like structures of unknown differentiation and cystic cavities filled with finely granular eosinophilic material [21]. Occasionally, the tumors develop near a nerve trunk. Exceptionally, the intraneural growth of cylindromas has been described in the literature. The tumors often present hybrid features (for example spiradenocylindroma) [22]. Spiradenocarcinoma, the malignant variant may occur in the following two scenarios: either in association with a spiradenoma, a case in which the transition between the two components is abrupt, or it may be recognized as a low grade tumor which retains the lobular architecture of spiradenomas, but has frank cytologic atypia [19].

Trichoepitheliomas are skin-colored, firm nodules, usually less than $2 \mathrm{~cm}$ in diameter. In patients with the MFT phenotype (multiple familial trichoepitheliomas), they are usually confined to the face, with confluence of the lesions in the nasolabial folds and also in the inner aspects of the eyebrow. Rapid enlargement of trichoepitheliomas may suggest a malignant transformation, usually as basal cell carcinoma [9].

Histologically, they are nodular, well-circumscribed tumors, which are believed to have dual differentiation towards both the follicular mesenchyme and the germinative follicular epithelium. The epithelial component consists of basaloid cells arranged in a lobular pattern, similar to those from basal cell carcinoma, with cribriform aspects, due to the presence of numerous horn cysts. Nevertheless, in trichoepithelioma, the perilobular stroma is more conspicuous and is frequently associated with the formation of round or oval fibroblastic aggregates. Another suggestive feature is the presence of mesenchymal bodies that represent hypercellular fibroblastic invaginations in the tumoral lobules, similar to the mesenchymal structures present in the hair follicle papillae [19].

The lesions noticed in association with Brooke-Spiegler syndrome include adenomas of the parotid gland, sebaceous nevi, basal cell carcinomas, different follicular-cystic entities, milium cysts, and xeroderma pigmentosum [23,24]. As we noticed in this report, in the case of a patient, trichoepitheliomas, cylindromas, and spiradenomas were accompanied by the development of a superficial basal cell carcinoma.

In patients with the MFT phenotype, the trichoepitheliomas are usually confined to the face and sometimes manifest an X-like distribution, with a confluence of the lesions in the nasolabial folds and also in the inner aspects of the eyebrow.

The surgical techniques used in the management of inherited hair-follicle-related tumors encompass: a classical excision, ablative laser, curettage, cryosurgery, electrosurgery, dermabrasion, as well as scalp excision with split-thickness skin grafting. As patients with Brooke-Spiegler Syndrome usually develop multiple neoplasms throughout their lifetime, repeated procedures may be needed. Although the main aim of surgery is tumor removal, taking wide surgical margins in order to prevent recurrence may not be feasible in patients with multiple lesions [25].

Ablative laser surgery offers a precise means of tumor removal. Its main indications are small facial lesions such as trichoepitheliomas. The tissue is vaporized in a controlled manner with excellent hemostasis. In one report, neodymium yttrium aluminum garnet (YAG) laser has been used similarly for larger scalp cylindromas [26].

Thanks to Mohs micrographic surgery, an insight into the real extent of these tumors has been provided.

In one case reported by Lo and colleagues, a sporadic cylindroma in the external auditory canal that measured $8 \mathrm{~mm}$ in diameter took five stages to achieve clearance [27]. Given the recurrence rate of these lesions estimated at $42 \%$ after excision [28], the Mohs technique remains the treatment that may offer the highest chance of clearance, but it is not feasible in the case of multiple tumors [27]. In this context, we believe that the treatment with $\mathrm{CO}_{2}$ laser remains a suitable option, which can be repeated 
in case of recurrent tumors, such as the case of the fourth patient presented who constantly developed new cutaneous lesions.

Scalp cylindromas continue to be a therapeutic challenge because of the limited local tissue reservoir. A paradox in the treatment is that, although hair conservation is important for cosmesis, the remaining hairs are the potential source for future tumors. Irwin and colleagues have recommended excision of lesions smaller than $1 \mathrm{~cm}$ and electrocoagulation of larger tumors. Isolated scalp cylindromas treated in this manner often heal with a small contracted scar that is easily hidden by the surrounding hair [29].

In the case of the patient that presented with multiple cylindromas, the treatment consisted of the median incision, followed by the removal of the content by curettage, electrosurgery, and closure with surgical staples. This conservative method remains a viable option taking into account the large number of lesions that characterize the disease.

Although the majority of neoplasms associated with Brooke-Spiegler syndrome are benign, malignant transformation does occur in 5 to 10 percent of cases. The finding draws attention to the importance of lifetime monitoring [6].

\section{Conclusions}

Considering the few numbers of Brooke-Spiegler syndrome cases in the current literature, the authors report these patients in order to increase awareness and to help establish the most appropriate approach in managing the disease in terms of physical examination, histological findings, and treatment. Due to the risk of association with malignant tumors, close monitoring of patients with Brooke-Spiegler Syndrome plays an important role. Regarding the therapeutic approach, it remains a challenge because of the high number of lesions and their tendency to relapse. We obtained satisfactory results with electrocautery, tumor debulking and $\mathrm{CO}_{2}$ laser.

Author Contributions: Conceptualization: M.L., C.C., T.T. methodology: T.T., A.M.; validation, M.L., T.T. formal analysis, C.C.; investigation: A.M.; resources: A.Z., M.L. data curation: C.L.; writing-original draft preparation: M.L., A.Z.; writing—review and editing, C.C.; visualization, X.X.; supervision: M.L. All authors have read and agreed to the published version of the manuscript.

Funding: This research received no external funding.

Conflicts of Interest: The authors declare no conflict of interest. The funders had no role in the design of the study; in the collection, analyses, or interpretation of data; in the writing of the manuscript, or in the decision to publish the results.

\section{References}

1. Saggar, S.; Chernoff, K.A.; Lodha, S.; Horev, L.; Kohl, S.; Honjo, R.S.; Brandt, H.R.C.; Hartmann, K.; Celebi, J.T. CYLD mutations in familial skin appendage tumours. J. Med. Genet. 2008, 45, 298. [CrossRef]

2. Bowen, S.; Gill, M.; Lee, D.A.; Fisher, G.; Geronemus, R.G.; Vazquez, M.E.; Celebi, J.T. Mutations in the CYLD gene in Brooke-Spiegler syndrome, familial cylindromatosis, and multiple familial trichoepithelioma: Lack of genotype-phenotype correlation. J. Investig. Dermatol. 2005, 124, 919. [CrossRef]

3. Young, A.L.; Kellermayer, R.; Szigeti, R.; Teszas, A.; Azmi, S.; Celebi, J.T. CYLD mutations underlie Brooke-Spiegler, familial cylindromatosis, and multiple familial trichoepithelioma syndromes. Clin. Genet. 2006, 70, 246. [CrossRef] [PubMed]

4. van den Ouweland, A.M.; Elfferich, P.; Lamping, R.; van de Graaf, R.; van Veghel-Plandsoen, M.M.; Franken, S.M.; Houweling, A.C. Identification of a large rearrangement in CYLD as a cause of familial cylindromatosis. Fam. Cancer 2011, 10, 127. [CrossRef] [PubMed]

5. Puig, L.; Nadal, C.; Fernández-Figueras, M.T.; Alegre, M.; de Moragas, J.M. Brooke-Spiegler syndrome variant: Segregation of tumor types with mixed differentiation in two generations. Am. J. Dermatopathol. 1998, 20, 56-60. [CrossRef] [PubMed] 
6. Tantcheva-Poór, I.; Vanecek, T.; Lurati, M.C.; Rychly, B.; Kempf, W.; Michal, M.; Kazakov, D.V. Report of Three Novel Germline CYLD Mutations in Unrelated Patients with Brooke-Spiegler Syndrome, Including Classic Phenotype, Multiple Familial Trichoepitheliomas and Malignant Transformation. Dermatology 2016, 232, 30. [CrossRef] [PubMed]

7. Grossmann, P.; Vanecek, T.; Steiner, P.; Kacerovska, D.; Spagnolo, D.V.; Cribier, B.; Rose, C.; Vazmitel, M.; Carlson, J.A.; Emberger, M.; et al. Novel and recurrent germline and somatic mutations in a cohort of 67 patients from 48 families with Brooke-Spiegler syndrome including the phenotypic variant of multiple familial trichoepitheliomas and correlation with the histopathologic findings in 379 biopsy specimens. Am. J. Dermatopathol. 2013, 35, 34-44.

8. Sima, R.; Vanecek, T.; Kacerovska, D.; Trubac, P.; Cribier, B.; Rutten, A.; Vazmitel, M.; Spagnolo, D.V.; Litvik, R.; Vantuchova, Y.; et al. Brooke-Spiegler syndrome: Report of 10 patients from 8 families with novel germline mutations: Evidence of diverse somatic mutations in the same patient regardless of tumor type. Diagn. Mol. Pathol. 2010, 19, 83-91. [CrossRef]

9. Kazakov, V.D. Brooke-Spiegler Syndrome and Phenotypic Variants: An Update. Head Neck Pathol. 2016, 10, 125-130. [CrossRef]

10. Rathi, M.; Awasthi, S.; Budania, S.K.; Ahmad, F.; Dutta, S.; Kumar, A. Brooke-spiegler syndrome: A rare entity. Case Rep. Pathol. 2014, 2014, 231895. [CrossRef]

11. Saunders, H.; Tucker, P.; Saurine, T.; Watkins, F. Pedigree of multiple benign adnexal tumours of Brooke-Spiegler type. Australas. J. Dermatol. 2003, 44, 144-148. [CrossRef] [PubMed]

12. Hoang, L.; Black, M.M.; Robson, A. case of Brooke-Spiegler Syndrome. Australas. J. Dermatol. 2004, 45, 220-222.

13. Ponti, G.; Pellacani, G.; Seidenari, S.; Pollio, A.; Muscatello, U.; Tomasi, A. Cancer-associated genodermatoses: Skin neoplasms as clues to hereditary tumor syndromes. Crit. Rev. Oncol. Hematol. 2013, 85, $239-256$. [CrossRef]

14. Weyers, W.; Nilles, M.; Eckert, F.; Schill, W.B. Spiradenomas in Brooke-Spiegler syndrome. Am. J. Dermatopathol. 1993, 15, 156-161. [CrossRef]

15. Sellheyer, K. Spiradenoma and cylindroma originate from the hair follicle bulge and not from the eccrine sweat gland: An immunohistochemical study with CD200 and other stem cell markers. J. Cutan. Pathol. 2015, 42, 90-101. [CrossRef]

16. Evans, C.D. Turban tumour. Br. J. Dermatol. 1954, 66, 434-443. [CrossRef]

17. Kazakov, D.V.; Zelger, B.; Rütten, A.; Vazmitel, M.; Spagnolo, D.V.; Kacerovska, D.; Vanecek, T.; Grossmann, P.; Sima, R.; Grayson, W.; et al. Morphologic diversity of malignant neoplasms arising in preexisting spiradenoma, cylindroma, and spiradenocylindroma based on the study of 24 cases, sporadic or occurring in the setting of Brooke-Spiegler syndrome. Am. J. Surg. Pathol. 2009, 33, 705. [CrossRef]

18. Weedon, D. Tumors of cutaneous appendages. In Weedon's Skin Pathology, 3rd ed.; Churchill Livingstone Elsevier: London, UK, 2010; pp. 785-786.

19. Calonje, J.E.; Brenn, T.; Lazar, A.; Billings, S. Mckee's Pathology of the Skin, 5th ed.; Elsevier: Amsterdam, The Netherlands, 2019; pp. 1570-1573, 1657-1665.

20. Kersting, D.W.; Helwig, E.B. Eccrine spiradenoma. AMA Arch. Dermatol. 1956, 73, 199-227. [CrossRef]

21. Kanwaljeet, S.; Chatterjee, T. Eccrine spiradenoma: A rare adnexal tumor. Indian J. Cancer 2017, 54, 695-696. [CrossRef]

22. Goette, D.K.; McConnell, M.A.; Fowler, V.R. Cylindroma and eccrinespiradenoma coexistent in the same lesion. Arch. Dermatol. 1982, 118, 723-724. [CrossRef]

23. Poniecka, A.W.; Alexis, J.B. An immunohistochemical study of basal cell carcinoma and trichoepithelioma. Am. J. Dermatopathol. 1999, 21, 332-336. [CrossRef] [PubMed]

24. Carsuzaa, F.; Carloz, E.; Lebeuf, M.; Grob, J.J.; Arnoux, D. Trichoépithéliomes multiples, cylindromes, grains de milium, dégénérescence carcinomateuse. Ann. Dermatol. Venereol. 1992, 119, 746-748.

25. Rajan, N.; Trainer, A.H.; Burn, J.; Langtry, J.A.A. Familial Cylindromatosis and Brooke-Spiegler Syndrome: A Review of Current Therapeutic Approaches and the Surgical Challenges Posed by Two Affected Families. Dermatol. Surg. 2009, 5, 845-852. [CrossRef] [PubMed]

26. Tarstedt, M.; Molin, L. Nd:YAG laser for effective treatment of multiple cylindroma of the scalp. J. Cosmet. Laser Ther. 2004, 6, 41-43. [CrossRef] [PubMed] 
27. Lo, J.S.; Snow, S.N.; Mohs, F.E. Cylindroma treated by Mohs micrographic surgery. J. Dermatol. Surg. Oncol. 1991, 17, 871-874. [CrossRef]

28. Crain, R.C.; Helwig, E.B. Dermal cylindroma (dermal eccrine cylindroma). Am. J. Clin. Pathol. 1961, 35, 504-515. [CrossRef]

29. Irwin, L.R.; Bainbridge, L.C.; Reid, C.A.; Piggot, T.A.; Brown, H.G. Dermal eccrine cylindroma (turban tumour). Br. J. Plast. Surg. 1990, 43, 702-705. [CrossRef] 